\title{
Liddle-Mutation of the $\beta$-Subunit, but not the $\gamma$-Subunit, Attenuates Protein Kinase C-Mediated Inhibition of Human Epithelial Sodium Channels (hENaC)
}

\author{
Gerard G. Robins ${ }^{1}$ - Geoffrey I. Sandle ${ }^{1}$
}

Received: 6 November 2015/Accepted: 18 December 2015/Published online: 12 January 2016

(C) The Author(s) 2016. This article is published with open access at Springerlink.com

\begin{abstract}
Mammalian distal nephron and distal colon, prime sites for $\mathrm{Na}^{+}$homeostasis, contain amiloride-sensitive epithelial sodium channels $(\mathrm{ENaC})$. Protein kinase $\mathrm{C}$ (PKC) inhibits $\mathrm{ENaC}$ by phosphorylating serine and threonine residues within $\mathrm{COOH}$ termini of the $\beta$ - and/or $\gamma$ subunits. Although some of these phosphorylation sites are close to the PY motifs, it is unclear whether they remain susceptible to PKC in Liddle-mutated $\mathrm{ENaC} \beta$ - and/or $\gamma$ subunits, where PY motifs are truncated, resulting in increased apical ENaC expression. We therefore studied the effects of PKC in wild-type and Liddle-mutated human epithelial $\mathrm{Na}^{+}$channels (hENaC) expressed in Xenopus oocytes, using the dual-electrode voltage clamp technique. PKC activation using $500 \mathrm{nmol} / \mathrm{l}$ phorbol 12-myristate 13 -acetate (PMA) decreased amiloride-sensitive $\mathrm{Na}^{+}$currents by $80 \%$ in oocytes expressing wild-type $\mathrm{hENaC}$, an effect largely prevented by co-exposure to $50 \mu \mathrm{mol} / \mathrm{l} \mathrm{cal}$ phostin C (a specific inhibitor of PKC), whereas $500 \mathrm{nmol} /$ 1 phorbol didecanoate (PDD), an inactive phorbol ester which does not stimulate PKC, had no effect. In oocytes expressing $\mathrm{hENaC}$ containing the Liddle-mutated $\beta$-subunit, PMA elicited a $54 \%$ decrease in amiloride-sensitive $\mathrm{Na}^{+}$currents, significantly $(P<0.0025)$ less than that in oocytes expressing wild-type $\mathrm{hENaC}$. By contrast, in oocytes expressing $\mathrm{hENaC}$ containing the Liddle-mutated $\gamma$-subunit, PMA elicited a $68 \%$ decrease in amiloridesensitive $\mathrm{Na}^{+}$current, similar $(P=0.10)$ to that in oocytes expressing wild-type hENaC. We conclude that hENaC
\end{abstract}

Geoffrey I. Sandle

g.i.sandle@leeds.ac.uk

1 Leeds Institute of Biomedical and Clinical Sciences, St James's University Hospital, Level 7, Clinical Sciences Building, Beckett Street, Leeds LS9 7TF, UK incorporating the Liddle-mutated $\beta$-subunit lacks one or more PKC phosphorylation sites, thereby significantly reducing the inhibitory effect of PKC on $\mathrm{Na}^{+}$channel activity, whereas hENaC incorporating Liddle-mutated $\gamma$ subunits remains as susceptible to PKC as wild-type hENaC.

Keywords $\mathrm{ENaC} \cdot$ Liddle mutations $\cdot$ Oocytes $\cdot$ Protein kinase $\mathrm{C} \cdot$ Sodium channels

\section{Introduction}

Apical membrane $\mathrm{Na}^{+}$channels $(\mathrm{ENaC})$ are expressed in many $\mathrm{Na}^{+}$absorptive epithelia, including the distal nephron, distal colon, lung, urinary bladder, salivary gland ducts, and sweat glands. The distal nephron and distal colon in particular function as " $\mathrm{Na}^{+}$scavengers," and have important roles in maintaining $\mathrm{Na}^{+}$(and thus water) homeostasis. In these epithelia, the rapid up-regulation of $\mathrm{ENaC}$ is one of the mechanisms invoked to compensate for the fluid losses that occur secondary to hemorrhage, infective and other types of secretory diarrhea, high-output ileostomies, and during periods of sustained exercise and fluid restriction. Such rapid responses are dependent on a number of extrinsic (e.g., aldosterone and arginine vasopressin) and intrinsic (e.g., ENaC trafficking, deubiquitination, and protein kinase A-mediated phosphorylation) factors, which increase $\mathrm{ENaC}$ synthesis, expression, and/or function (Bhalla and Hallows 2008). However, basal ENaC activity is also tightly regulated to prevent volume expansion and hypertension, and protein kinase $\mathrm{C}$ (PKC)mediated inhibition of $\mathrm{ENaC}$ expression and activity via the mitogen-activated protein kinase/ERK pathway is one potential mechanism (Zeissig et al. 2008). Studies in a 
variety of epithelia and planar lipid bilayers have shown that the activation of PKC $\left(\mathrm{a} \mathrm{Ca}^{2+}\right.$ - and phospholipid-dependent protein kinase) reduced $\mathrm{ENaC}$ activity by decreasing both open channel probability (Ling and Eaton 1989; Ling et al. 1992; Oh et al. 1993; Awayda et al. 1996) and channel density (Els et al. 1998). In renal A6 cells, the PKC-mediated decrease in ENaC activity appeared to reflect effects on ENaC $\beta$ - and $\gamma$-subunits, but not the $\alpha$ subunit (Stockand et al. 2000). Phorbol 12-myristate 13-acetate (PMA), a phorbol ester that activates PKC, also stimulated phosphorylation of rat ENaC $\beta$ - and $\gamma$-subunits (Shimkets et al. 1998). Human, rat, and Xenopus ENaC possess five conserved phosphorylation sites, one on each $\mathrm{COOH}$-terminus near the PY motif of the $\beta$ - and $\gamma$-subunits, and one on each $\mathrm{NH}_{2}$-terminus of both subunits, although the $\mathrm{COOH}$-terminus of the $\beta$-subunit appears to be a poor substrate for PKC-mediated phosphorylation (McDonald et al. 1995; Barbry and Hofman 1997). In addition, the $\mathrm{COOH}$-terminus of human $\mathrm{ENaC} \gamma$-subunit is predicted to have a strong PKC phosphorylation site (McDonald et al. 1995).

Some people of African descent with salt-sensitive hypertension possess a mutation involving the replacement of threonine by methionine at position $594(\beta-\mathrm{T} 594 \mathrm{M})$ in the PKC consensus site of the ENaC $\beta$-subunit, which appears to be unrelated to the Liddle mutation of the $\beta$ subunit (Cui et al. 1997). Lymphocytes from these patients exhibited greater whole-cell $\mathrm{Na}^{+}$currents in response to the membrane-permeant cAMP analog 8-(4-chlorophenylthio) adenosine $3^{\prime}, 5^{\prime}$-cyclic monophosphate (8-cptcAMP) than lymphocytes from normotensive individuals expressing wild-type ENaC. Furthermore, PMA abolished 8-cpt-cAMP-stimulated $\mathrm{Na}^{+}$channel activity in lymphocytes expressing wild-type ENaC, whereas PMA had no effect in lymphocytes with homozygotic mutations, and heterozygotes exhibited an intermediate effect (Cui et al. 1997). The putative PKC phosphorylation site at position 594 is outside the PY motif, and while lymphocytes expressing the Liddle-mutated PY motif had larger basal $\mathrm{Na}^{+}$currents than controls, 8-cpt-cAMP had no additional stimulatory effect (Bubien et al. 1996). Since PKC phosphorylation sites exist near the PY motifs of the $\gamma$-subunit as well as the $\beta$-subunit (Barbry and Hofman 1997), it is conceivable that Liddle-mutated $\beta$ - and $\gamma$-subunits have defective PKC consensus sites, resulting in loss of a mechanism for down-regulating $\mathrm{Na}^{+}$channels. Thus, the aim of the present study was to evaluate the effect of PKC on amiloride-sensitive $\mathrm{Na}^{+}$currents in Xenopus oocytes expressing wild-type human $\mathrm{ENaC}(\mathrm{hENaC})$, Liddle-mutated hENaC $\beta$-subunit alone, Liddle-mutated hENaC $\gamma$ subunit alone, or Liddle-mutated $\mathrm{hENaC} \beta$-subunit and Liddle-mutated hENaC $\gamma$-subunit in combination.

\section{Methods}

\section{Preparation of cDNA Constructs and Microinjection into Xenopus Oocytes}

hENaC subunit cDNAs were incorporated into pMT3 vector (a gift of Dr. P. Snyder, University of Iowa, USA). The vector contained one of the three wild-type subunits, the $\beta$-subunit with a Liddle-type truncation ( $\beta 566 \mathrm{X})$, or the $\gamma$-subunit with a Liddle-type truncation ( $\gamma 576 \mathrm{X})$. Clones were amplified by transforming competent Escherichia coli grown on LB-ampicillin agar plates, the pMT3 vector being ampicillin resistant. Plasmids were prepared using a proprietary kit (QIAGEN). Female Xenopus laevis (European Xenopus Resource Centre, University of Portsmouth, Portsmouth, UK) were killed by a schedule 1 method approved by the UK Home Office. Ovaries were removed, washed in modified Barth's saline (MBS), and divided into clumps of 10-30 oocytes, which were separated using $\mathrm{Ca}^{2+}$-free Ringer's solution containing $1 \mathrm{mg} / \mathrm{ml}$ collagenase, as described previously (Canessa et al. 1993). Oocytes at Dumont stages V and VI were transferred to 96-well plates containing MBS, centrifuged (2100 rpm, $15 \mathrm{~min}$ ), and the nuclei microinjected with either $20 \mathrm{nl}$ of sterile distilled water, or $20 \mathrm{nl}$ of sterile distilled water containing (3.5 ng of each subunit cDNA) wild-type $\mathrm{hENaC}, \mathrm{hENaC}$ with the Liddle-mutated $\beta$-subunit, or $\mathrm{hENaC}$ with the Liddle-mutated $\gamma$-subunit. Injected oocytes were transferred to 24-well plates containing MBS $\left(96 \mathrm{mmol} / 1 \mathrm{Na}^{+}\right)$and incubated at $19{ }^{\circ} \mathrm{C}$ for $24-48 \mathrm{~h}$.

\section{Dual-Electrode Voltage Clamp Recording}

Oocytes were superfused $(1 \mathrm{ml} / \mathrm{min})$ with a solution containing (in mmol/l): $\mathrm{Na}^{+}$gluconate $100, \mathrm{Ca}^{2+} 0.38, \mathrm{Mg}^{2+}$ 0.47, $\mathrm{Cl}^{-}$11.7, and HEPES 4.6 (pH 7.4), with $\mathrm{Ba}^{2+} 5.0$ and tetraethylammonium 10 to block endogenous $\mathrm{K}^{+}$channels. Oocytes were impaled with the voltage and current electrodes (tip resistances $<1 \mathrm{M} \Omega$ ) fabricated from glass microcapillary tubing and back-filled with $3 \mathrm{~mol} / \mathrm{K} \mathrm{KCl}$. Experiments were done at room temperature $\left(20-22{ }^{\circ} \mathrm{C}\right)$. When membrane voltage was stable, command voltages $(-140$ to $+40 \mathrm{mV}$ in $20 \mathrm{mV}$ increments) were applied for $500 \mathrm{~ms}$ from a holding voltage of $-10 \mathrm{mV}$, using a Labmaster TL40 interface and pClamp 5.6 software (Axon Instruments Inc., Union City, CA, USA). Whole-cell currents were measured twice, filtered at $100 \mathrm{~Hz}$, averaged, and stored for later analysis. The protocol was repeated after exposing oocytes to $10 \mu \mathrm{mol} / \mathrm{l}$ amiloride for $30 \mathrm{~s}$. This relatively high concentration of amiloride was used to ensure maximal inhibition of whole-cell $\mathrm{Na}^{+}$currents in oocytes expressing hENaC (Canessa et al. 1993). Differences between the pre- and post-amiloride whole-cell currents 
at each command voltage were taken to reflect whole-cell $\mathrm{Na}^{+}$ currents. After washing off amiloride, an additional set of whole-cell current measurements were obtained at each command voltage.

\section{Agents Used to Study hENaC Regulation by PKC}

To determine the effects of PKC, amiloride-sensitive whole-cell currents were measured using the above protocol, first in the absence and then after exposing the oocytes to $500 \mathrm{nmol} / 1 \mathrm{PMA}$ for $30 \mathrm{~min}$ to activate PKC. In preliminary experiments, using oocytes expressing wild-type $\mathrm{hENaC}$, the changes in amiloride-sensitive whole-cell currents produced by PMA had reached a steady-state at this time point. To provide 'negative control' data, similar experiments were performed with $500 \mathrm{nmol} / \mathrm{l}$ phorbol didecanoate (PDD), an inactive phorbol ester which does not stimulate PKC. Additional experiments were done with a combination of $500 \mathrm{nmol} / \mathrm{l} \mathrm{PMA}$ and $50 \mu \mathrm{mol} / \mathrm{l}$ calphostin C, a specific inhibitor of PKC (Hartzell and Rinderknecht 1996). 'Time control' experiments were performed with cDNA-injected oocytes to exclude possible 'run-down' of the whole-cell $\mathrm{Na}^{+}$currents.

\section{Statistical Analyses}

Data are shown as mean \pm SEM. Normalized amiloridesensitive whole-cell $\mathrm{Na}^{+}$currents at $-100 \mathrm{mV}$ were compared using either Student's $t$ test (for two sets of data), or one-way ANOVA with post hoc analysis (for more than two sets of data). Current-voltage relationships were compared using repeated measures ANOVA. $P<0.05$ was taken to indicate a statistically significant difference between two mean values. Data were analyzed using SPSS for Windows (release 10.1).

\section{Results}

\section{Effect of PKC on Wild-Type Human Renal ENaC}

Initial experiments were done in oocytes expressing wildtype hENaC to evaluate the changes in amiloride-sensitive whole-cell currents produced by $30 \mathrm{~min}$ exposure to 500 nmol/1 PMA. Amiloride largely abolished the prePMA whole-cell currents (Fig. 1a, b), consistent with $\mathrm{Na}^{+}$ channel inhibition. In the absence of amiloride, post-PMA whole-cell currents were markedly reduced compared with the pre-PMA whole-cell currents (Fig. 1a, c), and the residual currents were abolished by amiloride (Fig. 1c, d). With each oocyte, normalization of the post-PMA data to data obtained in the basal (pre-PMA) state indicated that PMA decreased amiloride-sensitive $\mathrm{Na}^{+}$currents in oocytes expressing wild-type hENaC by $80 \pm 3 \%$ at $-100 \mathrm{mV}$ ( $n=23 ; P<0.001$ ), whereas there was no significant change in cDNA-injected 'time control' oocytes $(n=12)$. These results were in agreement with those of previous studies, which demonstrated that PKC activation significantly decreased amiloride-sensitive $\mathrm{Na}^{+}$channel activity (Ling et al. 1992; Awayda et al. 1996; Awayda 2000).

\section{Effect of PDD on Wild-Type Human Renal ENaC}

'Negative control' experiments were done in oocytes expressing wild-type $\mathrm{hENaC}$ to evaluate amiloride-sensitive $\mathrm{Na}^{+}$currents after $30 \mathrm{~min}$ exposure to $500 \mathrm{nmol} / 1$ PDD, an inactive phorbol ester which does not activate PKC. As expected, amiloride markedly decreased the prePDD whole-cell currents (Fig. 2a, b). In the absence of amiloride, post-PDD whole-cell currents were similar to the pre-PDD whole-cell currents (Fig. 2a, c), but decreased markedly with the subsequent addition of amiloride (Fig. 2c, d). Normalization of the post-PDD data to data obtained in the basal (pre-PDD) state indicated that PDD had no significant effect on amiloride-sensitive $\mathrm{Na}^{+}$currents in oocytes expressing wild-type $\operatorname{hENaC}(n=6)$.

\section{Effect of PMA + Calphostin C on Wild-Type Human Renal ENaC}

In further experiments, the protocol with PMA in oocytes expressing wild-type $\mathrm{hENaC}$ was repeated with both $500 \mathrm{nmol} / \mathrm{l} \mathrm{PMA}$ and $50 \mu \mathrm{mol} / 1$ calphostin C (a specific PKC inhibitor) in the superfusing solution. Whereas PMA alone markedly decreased whole-cell currents in the absence of amiloride (Fig. 1a, c), this effect was attenuated when PMA was applied in the presence of calphostin $\mathrm{C}$ (Fig. 3a, c). The combination of PMA and calphostin $\mathrm{C}$ produced a $35 \pm 7 \%$ decrease in amiloride-sensitive $\mathrm{Na}^{+}$ current at $-100 \mathrm{mV}(n=8, P<0.03)$, and one-way ANOVA and post hoc analyses indicated that this change was significantly less than the $80 \pm 3 \%$ decrease produced by PMA alone $(P<0.001)$. The decrease in amiloride-sensitive $\mathrm{Na}^{+}$current produced by PMA and calphostin $\mathrm{C}$ also differed significantly $(P<0.001)$ from the small decrease in $\mathrm{Na}^{+}$current in the 'time control' experiments (Fig. 5a). Thus, our results indicate that calphostin $\mathrm{C}$ had a substantial inhibitory effect on the ability of PMA to decrease wild-type $\mathrm{Na}^{+}$channel activity.

\section{Effect of PMA on Liddle-Mutated Human Renal ENaC}

Since the $\mathrm{COOH}$ termini of wild-type hENaC $\beta$ - and $\gamma$ subunits contain potential PKC phosphorylation sites (Shimkets et al. 1998), additional experiments were done to 


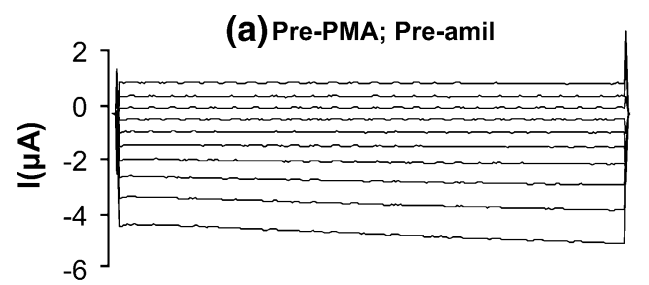

(c)Post-PMA; Pre-amil

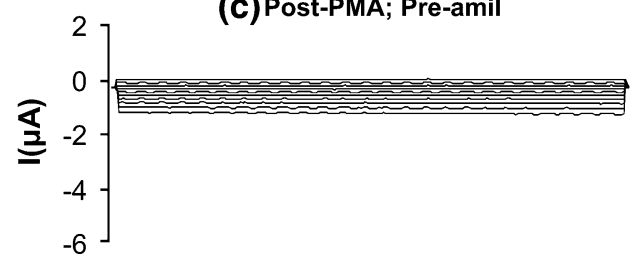

Fig. 1 Whole-cell currents (command voltages applied for $500 \mathrm{~ms}$ between -140 and $+40 \mathrm{mV}$ in $20 \mathrm{mV}$ increments) in an oocyte expressing wild-type $\mathrm{hENaC}$ a in the absence of PMA and amiloride, $\mathbf{b}$ in the absence of PMA but in the presence of amiloride, $\mathbf{c}$ in the

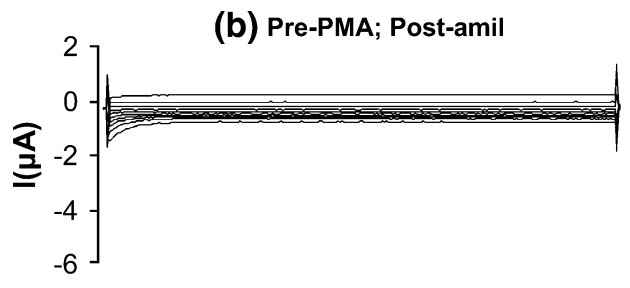

(d)Post-PMA; Post-amil

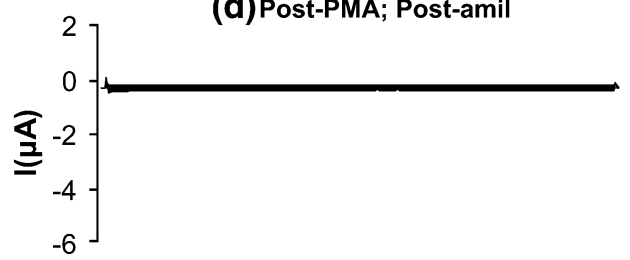

presence of PMA but in the absence of amiloride, and $\mathbf{d}$ in the presence of both PMA and amiloride. PMA markedly decreased oocyte amiloride sensitivity, consistent with inhibition of $\mathrm{hENaC}$
Fig. 2 Whole-cell currents (command voltages applied for $500 \mathrm{~ms}$ between -140 and $+40 \mathrm{mV}$ in $20 \mathrm{mV}$ increments) in an oocyte expressing wildtype $\mathrm{hENaC} \mathbf{a}$ in the absence of PDD and amiloride, $\mathbf{b}$ in the absence of PDD but in the presence of amiloride, $\mathbf{c}$ in the presence of PDD but in the absence of amiloride, and $\mathbf{d}$ in the presence of both PDD and amiloride. PDD had no effect on oocyte amiloride sensitivity
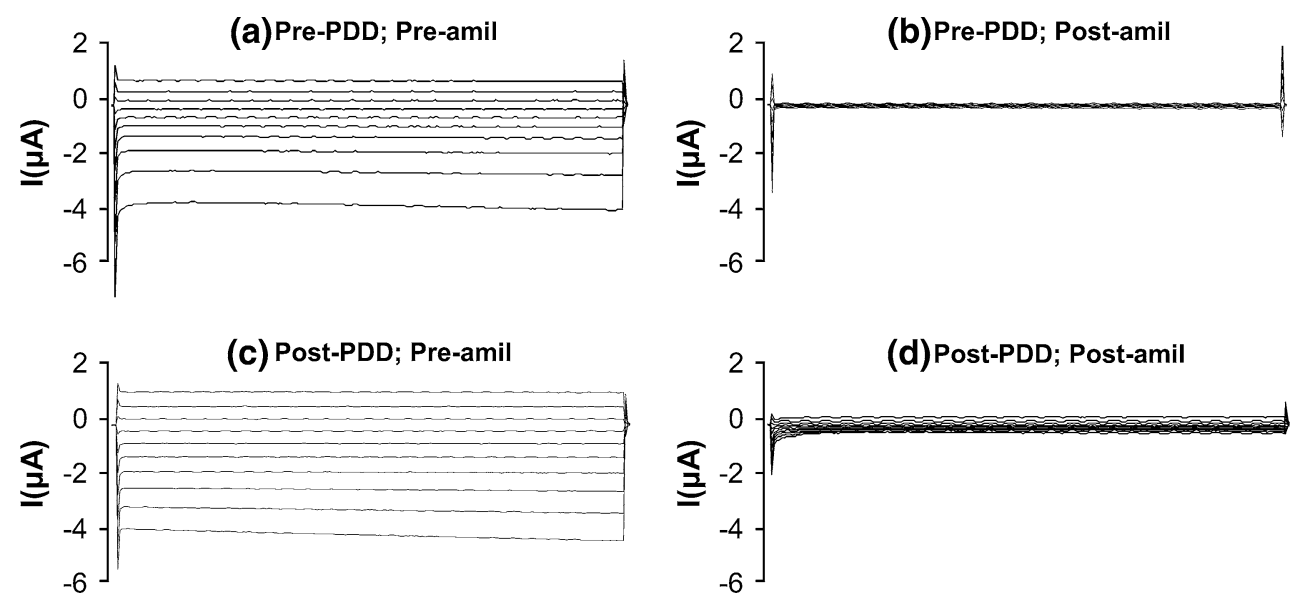
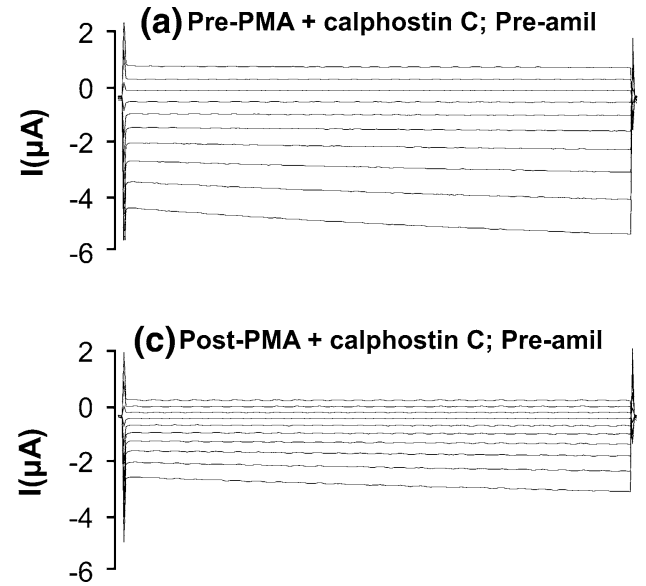

Fig. 3 Whole-cell currents (command voltages applied for $500 \mathrm{~ms}$ between -140 and $+40 \mathrm{mV}$ in $20 \mathrm{mV}$ increments) in an oocyte expressing wild-type hENaC a in the absence of PMA + calphostin C and amiloride, $\mathbf{b}$ in the absence of PMA + calphostin $\mathrm{C}$ but in the presence of amiloride, $\mathbf{c}$ in the presence of PMA + calphostin $\mathrm{C}$ but
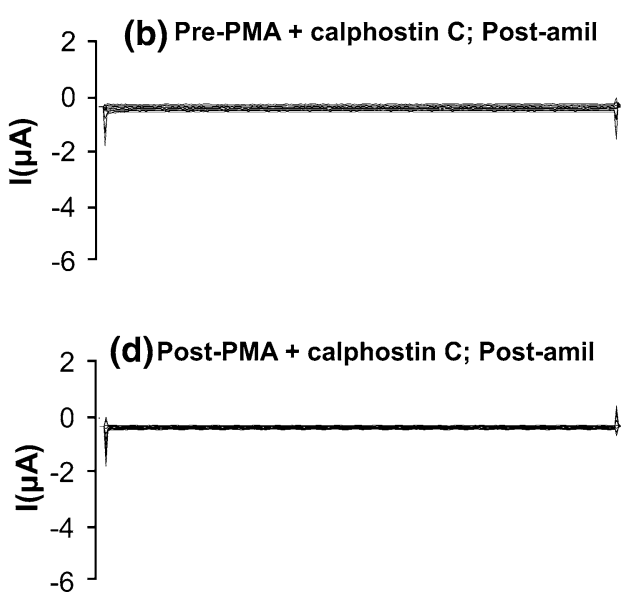

in the absence of amiloride, and $\mathbf{d}$ in the presence of both PMA + calphostin C and amiloride. Calphostin C significantly reduced the decrease in oocyte amiloride sensitivity produced by PMA alone (see Fig. 1 for comparison) 
evaluate the effect of PMA on hENaC containing the Liddle-mutated $\beta$ - and $\gamma$-subunits. The small and insignificant decreases in amiloride-sensitive $\mathrm{Na}^{+}$currents seen with wild-type hENaC in 'time control' oocytes and those exposed to PDD were identical, and thus only 'time controls' were used for the experiments with Liddle-mutated hENaC. Basal amiloride-sensitive $\mathrm{Na}^{+}$currents in oocytes expressing the Liddle-mutated $\beta$-subunit (Fig. 4a, $\mathrm{b} ; n=14$ ) or the Liddle-mutated $\gamma$-subunit (Fig. 4e, f; $n=16$ ) were substantially greater than those expressing wild-type hENaC (Fig. 1a, b), as reported previously (Hansson et al. 1995; Robins et al. 2013; Robins and Sandle 2014). Furthermore, basal amiloride-sensitive $\mathrm{Na}^{+}$ currents in oocytes expressing both the Liddle-mutated $\beta$ and the $\gamma$-subunits (Fig. 4i, j; $n=9$ ) were almost an order of magnitude greater than in those expressing the Liddlemutated $\beta$ - or the $\gamma$-subunit alone, as reported by others (Hansson et al. 1995).

In the absence of amiloride, PMA decreased whole-cell currents in oocytes expressing the Liddle-mutated $\beta$-subunit (Fig. 4a, c), but to a smaller degree than in oocytes expressing wild-type hENaC (Fig. 1a, c), Nevertheless, at $-100 \mathrm{mV}$, PMA elicited a significant $54 \pm 4 \%(n=14$; $P<0.001)$ decrease in amiloride-sensitive whole-cell $\mathrm{Na}^{+}$ currents in oocytes expressing the Liddle-mutated $\beta$-subunit (Fig. 4a-d). One-way ANOVA followed by post hoc analyses indicated that the decrease in response to PMA in oocytes expressing the Liddle-mutated $\beta$-subunit $(54 \pm 4 \%)$ was significantly less than that in oocytes expressing wild-type hENaC $(80 \pm 3 \% ; P<0.0025)$. In the absence of amiloride, PMA also decreased whole-cell currents in oocytes expressing the Liddle-mutated $\gamma$-subunit (Fig. 4e, g), almost to the same degree as that seen in oocytes expressing wild-type hENaC (Fig. 1a, c). At $-100 \mathrm{mV}$, PMA elicited a $68 \pm 5 \%$ decrease $(n=16 ; P<0.001)$ in amiloride-sensitive whole-cell $\mathrm{Na}^{+}$currents in oocytes expressing the Liddle-mutated $\gamma$-subunit (Fig. 4e-h), and one-way ANOVA followed by post hoc analyses indicated that this decrease was similar to that in oocytes expressing wild-type hENaC $(80 \pm 3 \% ; P=0.10)$.

Additional experiments were performed using oocytes co-expressing both the Liddle-mutated $\beta$-subunit and the Liddle-mutated $\gamma$-subunit of hENaC. In the absence of amiloride, PMA decreased whole-cell currents in these oocytes (Fig. 4i, k) almost to the same degree as that seen in oocytes expressing the Liddle-mutated $\beta$-subunit alone (Fig. 4a, c). At $-100 \mathrm{mV}$, PMA elicited a significant $37 \pm$ $5 \%(n=9 ; P<0.0025)$ decrease in amiloride-sensitive whole-cell $\mathrm{Na}^{+}$currents in oocytes co-expressing the Liddle-mutated $\beta$ - and $\gamma$-subunits (Fig. 4i-1). One-way ANOVA followed by post hoc analyses indicated that the PMA-induced decrease in amiloride-sensitive whole-cell $\mathrm{Na}^{+}$currents in oocytes co-expressing the Liddle-mutated $\beta$ - and $\gamma$ - subunits was significantly less than in oocytes expressing wild-type $\mathrm{hENaC}$ or the Liddle-mutated $\gamma$-subunit alone $(P<0.002$ in both cases), but was similar to the decrease in oocytes expressing the Liddle-mutated $\beta$-subunit alone $(P=0.08)$.

\section{Summary of Wild-Type Human Renal ENaC Data}

Normalized amiloride-sensitive $\mathrm{Na}^{+}$currents from each protocol in oocytes expressing wild-type $\mathrm{hENaC}$ are summarized in Fig. 5a. In each case, the left-hand bar indicates normalized data at time zero in 'time control' experiments, and in the presence of PMA alone, PDD, or PMA + calphostin C. In contrast to the 'time control' experiments, PMA elicited a $80 \pm 3 \%$ decrease in amiloride-sensitive $\mathrm{Na}^{+}$current $(P<0.001)$, whereas there was no significant change with PDD $(P=0.121)$, and PMA + calphostin C elicited a smaller but significant $35 \pm 7 \%$ decrease in amiloride-sensitive $\mathrm{Na}^{+}$current $(P<0.03)$ compared with PMA alone. One-way ANOVA and post hoc analyses indicated that, compared with the response to PMA alone, those with PMA + calphostin and PDD were significantly different $(P<0.001$ in both cases). Taken together, these results indicate that the inhibitory effect of PMA on wildtype $\mathrm{hENaC}$ is mediated by activation of PKC rather than via a nonspecific effect of the phorbol ester.

\section{Summary of Liddle-Mutated Human Renal ENaC Data}

Normalized amiloride-sensitive $\mathrm{Na}^{+}$currents from oocytes expressing the Liddle-mutated $\beta$-subunit, the Liddle-mutated $\gamma$-subunit, or both the Liddle-mutated $\beta$-subunit and the Liddle-mutated $\gamma$-subunit, are summarized in Fig. 5b. In each case, the left-hand bar indicates normalized data at time zero in the three groups of oocytes expressing the Liddlemutated subunits treated with PMA. In contrast to the "time control' experiments, PMA elicited decreases in amiloridesensitive $\mathrm{Na}^{+}$current in oocytes expressing the Liddle-mutated $\beta$-subunit, the Liddle-mutated $\gamma$-subunit, or both the Liddle-mutated $\beta$-subunit and the Liddle-mutated $\gamma$-subunit of $54 \pm 4 \% \quad(P<0.001), 68 \pm 5 \% \quad(P<0.001)$, and $37 \pm 5 \%(P<0.0025)$, respectively. One-way ANOVA followed by post hoc analyses indicated that, compared with the PMA-induced decrease in amiloride-sensitive $\mathrm{Na}^{+}$current in oocytes expressing wild-type $\mathrm{hENaC}(80 \pm 3 \%)$, the decreases in oocytes expressing Liddle-mutated $\beta$-subunit (54 $\pm 4 \%$ ), or both the Liddle-mutated $\beta$-subunit and the Liddle-mutated $\gamma$-subunit $(37 \pm 5 \%)$ were significantly less $(P<0.0025$ and $P<0.002$, respectively). By contrast, the decrease in oocytes expressing the Liddle-mutated $\gamma$ subunit $(68 \pm 5 \%)$ was similar to that in oocytes expressing wild-type $\mathrm{hENaC}(P=0.1)$. 


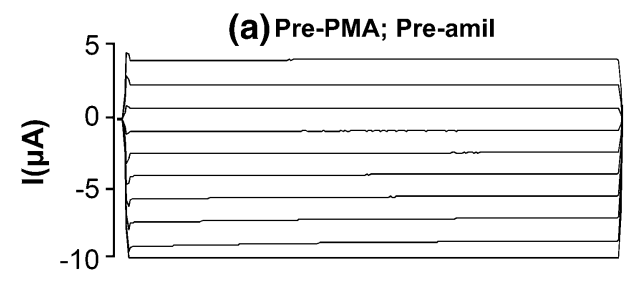

(c) Post-PMA; Pre-amil
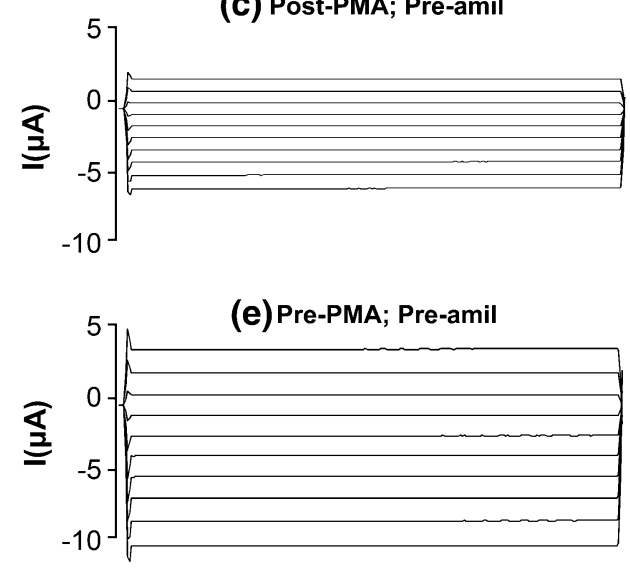

(g) Post-PMA; Pre-amil
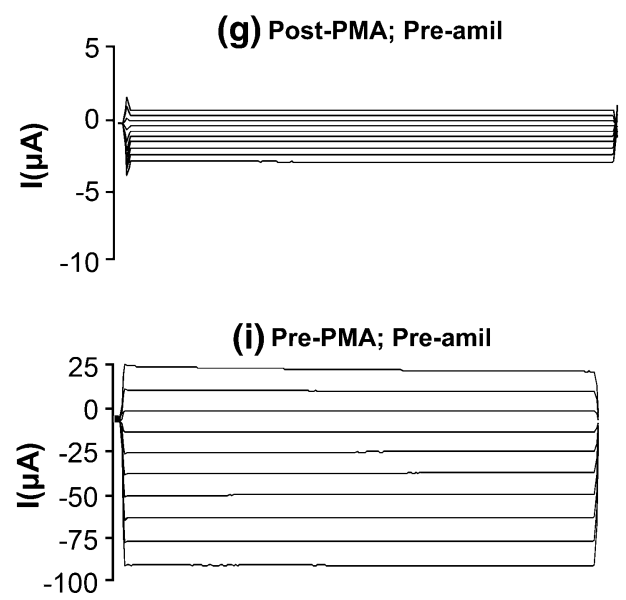

(k)Post-PMA; Pre-amil

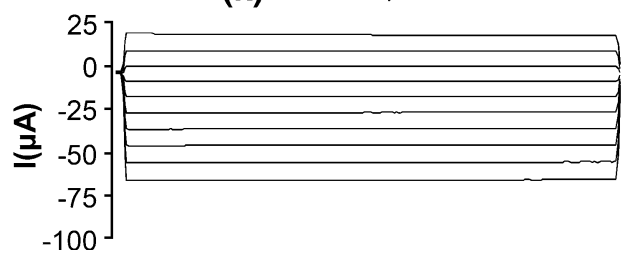

Fig. 4 Whole-cell currents (command voltages applied for $500 \mathrm{~ms}$ between -140 and $+40 \mathrm{mV}$ in $20 \mathrm{mV}$ increments) in oocytes expressing a-d $\beta$-subunit Liddle-mutated hENaC, e-h $\gamma$-subunit Liddle-mutated hENaC, or $\mathbf{i}-\mathbf{l}$ both $\beta$ - and $\gamma$ subunit Liddle-mutated

\section{Discussion}

Previous studies in Madin-Derby canine kidney (MDCK) cells stably transfected with rat $\mathrm{ENaC} \alpha-, \beta-$, and $\gamma$-subunits have shown that whereas the $\beta$ - and $\gamma$-subunits (but

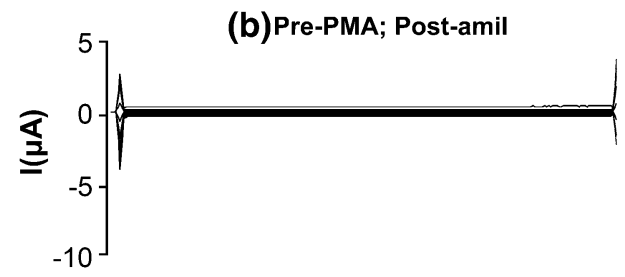

(d) Post-PMA; Post-amil
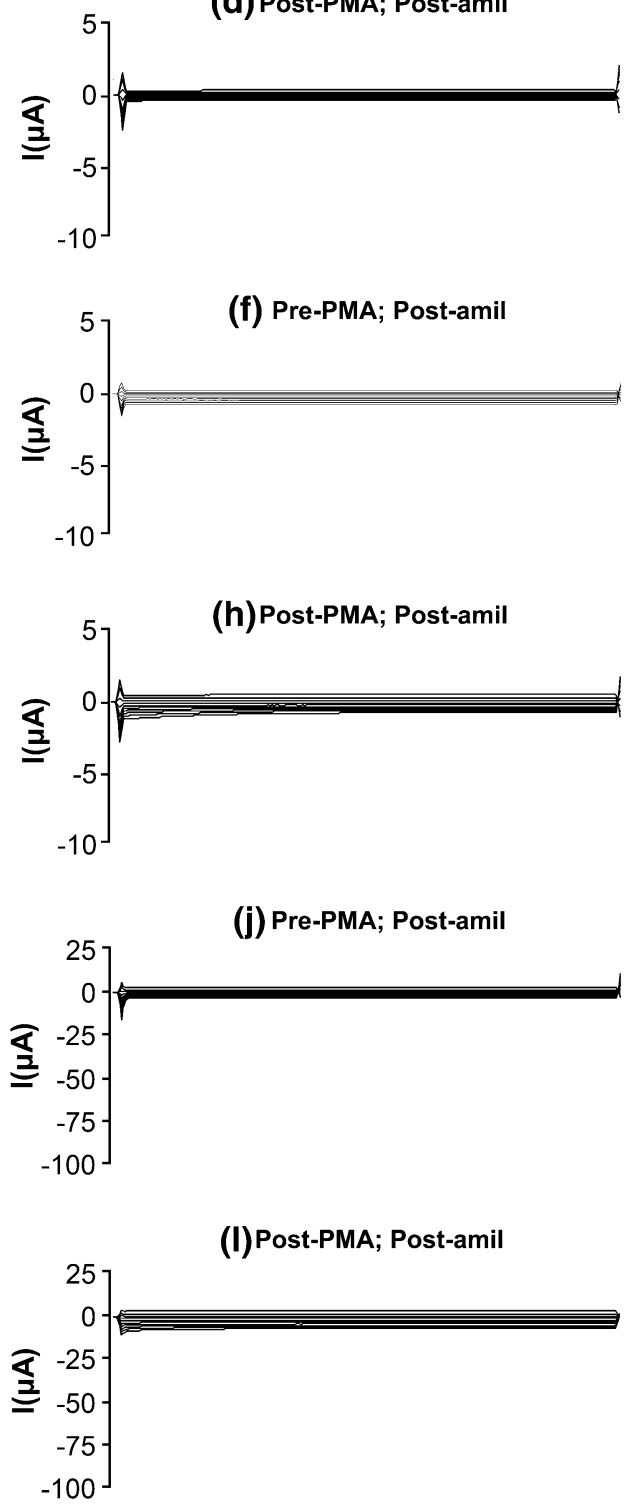

$\mathrm{hENaC}, \mathbf{a}, \mathbf{e}, \mathbf{i}$ in the absence of PMA and amiloride, $\mathbf{b}, \mathbf{f}, \mathbf{j}$ in the absence of PMA but in the presence of amiloride, $\mathbf{c}, \mathbf{g}, \mathbf{k}$ in the presence of PMA but in the absence of amiloride, and $(\mathbf{d}, \mathbf{h}, \mathbf{l})$ in the presence of both PMA and amiloride

not the $\alpha$-subunits) are phosphorylated under basal conditions, PKC enhances phosphorylation of the $\beta$ - and $\gamma$ subunits but not the $\alpha$-subunit, the sites of phosphorylation being serine and threonine residues within the $\mathrm{COOH}$ termini (Shimkets et al. 1998). Putative PKC phosphorylation 
Fig. 5 Summary of amiloridesensitive whole-cell $\mathrm{Na}^{+}$ currents (recorded at $-100 \mathrm{mV}$ ) in oocytes a expressing wildtype $\mathrm{hENaC}$ in time controls (open bars, $n=12$ ), and $30 \mathrm{~min}$ after the addition of PMA (diagonally hatched bars, $n=23$ ), PDD (solid bars, $n=6$ ), or PMA+ calphostin C (horizontally hatched bars, $n=8$ ), and $\mathbf{b}$ expressing Liddle-mutated $\beta$-subunit (diagonally hatched bars, $n=14$ ), Liddle-mutated $\gamma$ subunit (solid bars, $n=16$ ), or both Liddle-mutated $\beta$-and $\gamma$ subunits (horizontally hatched bars, $n=9$ ), 30 min after the addition of PMA, with accompanying time controls (open bars, $n=4$ )
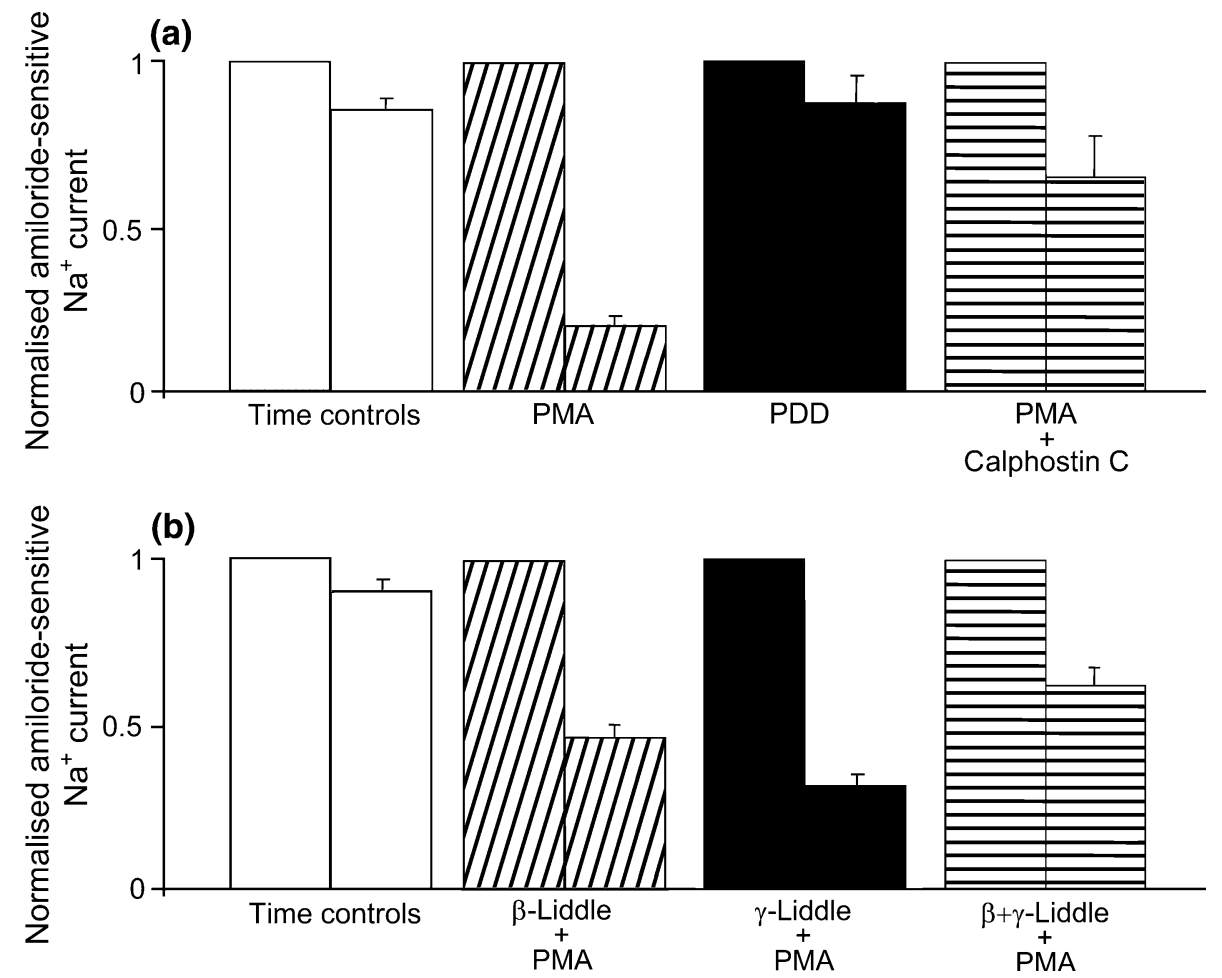

sites are located close to the PY motifs in the $\mathrm{COOH}$ termini of ENaC $\beta$ - and $\gamma$-subunits (Barbry and Hofman 1997), raising the possibility that $\mathrm{ENaC}$ containing Liddlemutated $\beta$ - and/or $\gamma$-subunits mutations might have an altered response to PKC activation. In the present study, we explored this possibility by studying the effect of PMAactivated PKC on amiloride-sensitive $\mathrm{Na}^{+}$currents in oocytes expressing wild-type $\mathrm{hENaC}$, and $\mathrm{hENaC}$ containing the Liddle-mutated $\beta$ - and $\gamma$-subunits, either alone or in combination. We found that PMA reduced amiloridesensitive $\mathrm{Na}^{+}$currents by $80 \%$ in oocytes expressing wildtype $\mathrm{hENaC}$, whereas the inactive phorbol ester PDD had no effect. In addition, the inhibitory effect of PMA-activated $\mathrm{PKC}$ on amiloride-sensitive $\mathrm{Na}^{+}$currents was attenuated by the PKC inhibitor calphostin C, the $35 \%$ decrease being significantly less $(P<0.001)$ than that produced by PMA alone. Thus, from these results, it is clear that PMA markedly decreased wild-type hENaC though a mechanism involving the activation of PKC. Our findings are consistent with those reported in renal A6 cells, in which PKC down-regulated $\mathrm{ENaC}$ by phosphorylating the $\beta$ - and $\gamma$-subunits, but not the $\alpha$-subunit (Stockand et al. 2000). PKC decreases both open channel probability (Ling and Eaton 1989; Ling et al. 1992; Oh et al. 1993; Awayda et al. 1996) and channel density (Els et al. 1998) of wild-type $\mathrm{ENaC}$, and similar changes may underlie the PMA-induced $80 \%$ decrease in amiloridesensitive $\mathrm{Na}^{+}$current we observed in oocytes expressing wild-type $\mathrm{hENaC}$, following PKC-mediated phosphorylation of the $\beta$ - and/or $\gamma$-subunits. We have previously shown that raising intracellular $\mathrm{Ca}^{2+}$ in oocytes expressing wildtype $\mathrm{hENaC}$ also decreases amiloride-sensitive $\mathrm{Na}^{+}$current by $55 \%$ through a W-7-sensitive (i.e., calmodulin-dependent) mechanism (Robins and Sandle 2014). However, it seems unlikely that the inhibitory effect of PMA-activated PKC on the amiloride-sensitive $\mathrm{Na}^{+}$currents was $\mathrm{Ca}^{2+}$ dependent, since PKC has $\mathrm{Ca}^{2+}$-independent effects in other cell types (Iacopetta et al. 1986; Bonaccorsi et al. 1998).

By contrast, in oocytes expressing the Liddle-mutated $\beta$ subunit, PMA decreased amiloride-sensitive $\mathrm{Na}^{+}$currents by only $54 \%$, a change significantly less than that seen in those expressing wild-type hENaC $(80 \% ; P<0.0025)$. Furthermore, in oocytes expressing the Liddle-mutated $\gamma$ subunit, PMA decreased amiloride-sensitive $\mathrm{Na}^{+}$currents by $68 \%$, a change that was not significantly different from the $80 \%$ decrease seen in oocytes expressing wild-type $\mathrm{hENaC}(P=0.1)$. In oocytes expressing hENaC containing both the Liddle-mutated $\beta$ - and the Liddle-mutated $\gamma$ subunits, PMA significantly decreased amiloride-sensitive $\mathrm{Na}^{+}$currents by $37 \%(P<0.0025)$, a change similar $(P=0.08)$ to that seen in oocytes expressing hENaC containing the Liddle-mutated $\beta$-subunit alone. Previous studies have indicated that PKC down-regulates both the $\beta$ and $\gamma$-subunits of wild-type hENaC (Stockland et al. 2000), presumably at the putative $\mathrm{PKC}$ phosphorylation sites 
present close to the PY motifs of their $\mathrm{COOH}$ termini (Barbry and Hofman 1997). Contrary to the suggestion that the $\beta$-subunit consensus site may be a poorer substrate for PKC-induced phosphorylation than the corresponding site on the $\gamma$-subunit (Barbry and Hofman 1997), our results indicate that it is the inclusion of the Liddle-mutated $\beta$ subunit, rather than the Liddle-mutated $\gamma$-subunit, which diminishes PKC's inhibitory effect on $\mathrm{hENaC}$.

An additional intracellular signaling mechanism to be considered when interpreting our data is that involving myristolated alanine-rich C kinase substrate (MARCKS) (Sengupta et al. 2007). MARCKS possesses sites for PKC phosphorylation (Hartwig et al. 1992) and acts as an adaptor protein, binding to and presenting phosphatidylinositol phosphates (PIPs; particularly phosphatidylinositol 4,5-biphosphate, PIP2) to regulate $\mathrm{ENaC}$ activity (Alli et al. 2012). In Xenopus 2F3 renal epithelial cells, MARCKS colocalizes with PIP2 at the apical membrane, but translocates to the cytoplasm after PKC stimulation, so that PKC-induced MARCKS phosphorylation decreases amiloride-sensitive $\mathrm{Na}^{+}$currents; conversely, inhibition of PKC-promoted binding of unphosphorylated MARCKS to PIPs for presentation to $\mathrm{ENaC}$ increases amiloride-sensitive $\mathrm{Na}^{+}$currents (Alli et al. 2012). Thus, in our experiments with hENaC (particularly the wild-type), PMAactivated PKC could have promoted translocation into the cytoplasm of MARCKS present in the oocyte membrane, thereby decreasing PIP-regulated $\mathrm{hENaC}$ activity.

Thus, we have shown that PKC produces substantial inhibition $(80 \%)$ of amiloride-sensitive $\mathrm{Na}^{+}$currents through wild-type $\mathrm{hENaC}$, and $\mathrm{Na}^{+}$currents through hENaC containing the Liddle-mutated $\gamma$-subunit are inhibited to a similar extent $(68 \%)$. By contrast, PKC produces much less inhibition $(54 \%)$ of $\mathrm{Na}^{+}$currents through hENaC containing the Liddle-mutated $\beta$-subunit, which suggests that the $\mathrm{COOH}$-terminus of this subunit (rather than the $\gamma$-subunit) possesses one or more phosphorylation sites, which are critical for the regulation of wild-type $\mathrm{hENaC}$ by PKC. Whether or not this apparent difference between the susceptibilities of the Liddle-mutated $\beta$-subunit and the Liddle-mutated $\gamma$-subunit to PKC has any clinical relevance is unclear, because the identification of specific Liddle $\beta$ - and $\gamma$-mutations has generally been restricted to individual patients or clusters of patients in a single family. However, a recent genetic study of 330 young Chinese hypertensive patients identified Liddle syndrome in five $(1.52 \%)$, and in 12 of their relatives (Wang et al. 2015). Of the five patients, four had Liddle $\beta$ subunit mutations, whereas only one had a Liddle $\gamma$-subunit mutation. If the $\beta$-subunit mutation predominates to a similar degree in cases of Liddle syndrome irrespective of ethnicity, it is possible that a significant impairment of $\mathrm{PKC}$-induced down-regulation of $\mathrm{ENaC}$ contributes to the salt-sensitive hypertension that characteristically occurs in these patients.

Acknowledgment This work was supported by a Grant from the British Heart Foundation.

Open Access This article is distributed under the terms of the Creative Commons Attribution 4.0 International License (http://crea tivecommons.org/licenses/by/4.0/), which permits unrestricted use, distribution, and reproduction in any medium, provided you give appropriate credit to the original author(s) and the source, provide a link to the Creative Commons license, and indicate if changes were made.

\section{References}

Alli AA, Bao HF, Alli AA et al (2012) Phosphatidylinositol phosphate-dependent regulation of Xenopus ENaC by MARCKS protein. Am J Physiol Renal Physiol 303:F800-F811

Awayda MS (2000) Specific and nonspecific effects of protein kinase $\mathrm{C}$ on the epithelial $\mathrm{Na}^{+}$channel. J Gen Physiol 115:559-570

Awayda MS, Ismailov II, Berdiev BK et al (1996) Protein kinase regulation of a cloned epithelial $\mathrm{Na}^{+}$channel. J Gen Physiol 108:49-65

Barbry P, Hofman P (1997) Molecular biology of $\mathrm{Na}^{+}$absorption. Am J Physiol Gastrointest Liver Physiol 273:G571-G585

Bhalla V, Hallows KR (2008) Mechanisms of ENaC regulation and clinical implications. J Am Soc Nephrol 19:1845-1854

Bonaccorsi L, Krausz C, Pecchioli P et al (1998) Progesteronestimulated intracellular calcium increase in human spermatozoa is protein kinase C-independent. Mol Hum Reprod 4:259-268

Bubien JK, Ismailov II, Berdiev BK et al (1996) Liddle's disease: abnormal regulation of amiloride-sensitive $\mathrm{Na}^{+}$channels by $\beta$ subunit mutation. Am J Physiol Cell Physiol 39:C208-C213

Canessa CM, Horisberger JD, Rossier BC (1993) Epithelial sodium channel related to proteins involved in neurodegeneration. Nature 361:467-470

Cui Y, Su YR, Rutkowski M et al (1997) Loss of protein kinase C inhibition in the $\beta$-T594M variant of the amiloride-sensitive $\mathrm{Na}^{+}$ channel. Proc Natl Acad Sci USA 94:9962-9966

Els WJ, Liu X, Helman SI (1998) Differential effects of phorbol ester (PMA) on blocker-sensitive $\mathrm{ENaCs}$ of frog skin and $\mathrm{A} 6$ epithelia. Am J Physiol Cell Physiol 275:C120-C129

Hansson JH, Nelson-Williams C, Suzuki H et al (1995) Hypertension caused by a truncated epithelial sodium channel $\gamma$ subunit: genetic heterogeneity of Liddle syndrome. Nat Genet 11:76-82

Hartwig JH, Thelen M, Rosen A et al (1992) MARCKS is an actin filament crosslinking protein regulated by protein kinase $\mathrm{C}$ and calcium/calmodulin. Nature 356:618-622

Hartzell HC, Rinderknecht A (1996) Calphostin C, a widely used protein kinase $\mathrm{C}$ inhibitor, directly and potently blocks L-type $\mathrm{Ca}$ channels. A J Physiol Cell Physiol 270:C1293-C1299

Iacopetta B, Carpentier JL, Pozzan T et al (1986) Role of intracellular calcium and protein kinase $\mathrm{C}$ in the endocytosis of transferrin and insulin by HL60 cells. J Cell Biol 103:851-856

Ling BN, Eaton DC (1989) Effects of luminal $\mathrm{Na}^{+}$on single $\mathrm{Na}^{+}$ channels in A6 cells, a regulatory role for protein kinase C. Am J Physiol Renal Physiol 256:F1094-F1103

Ling BN, Kokko KE, Eaton DC (1992) Inhibition of apical $\mathrm{Na}^{+}$ channels in rabbit cortical collecting tubules by basolateral prostaglandin $\mathrm{E}_{2}$ is modulated by protein kinase C. J Clin Investig 90:1328-1334 
McDonald FJ, Price MP, Snyder PM et al (1995) Cloning and expression of the $\beta$ - and $\gamma$-subunits of the human epithelial sodium channel. Am J Physiol Cell Physiol 268:C1157-C1163

Oh Y, Smith PR, Bradford AL et al (1993) Regulation by phosphorylation of purified epithelial $\mathrm{Na}^{+}$channels in planar lipid bilayers. Am J Physiol Cell Physiol 265:C85-C91

Robins GG, Sandle GI (2014) Calcium rapidy down-regulates human renal epithelial sodium channels via a W-7-sensitive mechanism. J Membr Biol 247:729-737

Robins GG, MacLennan KA, Boot-Handford RP et al (2013) Rapid stimulation of human renal ENaC by cAMP in Xenopus laevis oocytes. J Physiol Biochem 69:419-427

Sengupta P, Ruano ML, Tebar F et al (2007) membrane-permeable calmodulin inhibitors (e.g. W-7/W-13) bind to membranes, changing the electrostatic surface potential. Dual effect of W-13 on epidermal growth factor receptor activation. J Biol Chem 282:8474-8486

Shimkets RA, Lifton R, Canessa CM (1998) In vivo phosphorylation of the epithelial sodium channel. Proc Natl Acad Sci USA 95:3301-3305

Stockand JD, Bao HF, Schenk J et al (2000) Differential effects of protein kinase $\mathrm{C}$ on the levels of epithelial $\mathrm{Na}^{+}$channel subunit proteins. J Biol Chem 275:25760-25765

Wang LP, Yang KQ, Jiang XJ et al (2015) Prevalence of Liddle syndrome among young hypertension patients of undetermined cause in a Chinese population. J Clin Hypertension 17:902-907

Zeissig S, Bergann T, Fromm A et al (2008) Altered ENaC expression leads to impaired sodium absorption in the noninflamed intestine in Crohn's disease. Gastroenterology 134:1436-1447 